\title{
Prevention of amyloid B-induced memory impairment by fluvastatin, associated with the decrease in amyloid $B$ accumulation and oxidative stress in amyloid $\beta$ injection mouse model
}

\author{
HITOMI KURINAMI ${ }^{1,2}$, NAOYUKI SATO ${ }^{1,2}$, MITSURU SHINOHARA ${ }^{1,2}$, DAISUKE TAKEUCHI ${ }^{1,2}$, \\ SHUKO TAKEDA $^{1,2}$, MUNEHISA SHIMAMURA ${ }^{3}$, TOSHIO OGIHARA ${ }^{2}$ and RYUICHI MORISHITA ${ }^{1,2}$ \\ Departments of ${ }^{1}$ Clinical Gene Therapy, ${ }^{2}$ Geriatric Medicine, Graduate School of Medicine, \\ Osaka University, Yamada-oka, Suita; ${ }^{3}$ Department of Advanced Clinical Science and \\ Therapeutics, Graduate School of Medicine, The University of Tokyo, Tokyo, Japan
}

Received December 17, 2007; Accepted January 30, 2008

\begin{abstract}
Alzheimer's disease (AD), the most common cause of dementia in the elderly, is characterized by amyloid $\beta(A ß)$ containing plaques and neurofibrillary tangles, and synaptic and neuronal loss, along with progressive cognitive impairment. Although growing evidence suggests the beneficial effects of 3-hydroxy-3-methylglutaryl coenzyme A reductase inhibitors (statins) on $\mathrm{AD}$, this notion is still controversial. To evaluate the efficacy of statins for $A \beta$-induced cognitive impairment, we employed an $A B$ injection model. Using this model, the present study demonstrated that pretreatment with fluvastatin, but not post-treatment just after $A B$ exposure, prevented $A \beta$-induced memory impairment. We also observed that fluvastatin significantly decreased $A ß$ accumulation and oxidative stress after $A B$ injection. Mice treated with simvastatin, but not fluvastatin, did not demonstrate the prevention of $\mathrm{A} \beta$-induced memory impairment, and showed no significant decrease in oxidative stress. More importantly, fluvastatin significantly prevented the loss of neurons in the basal forebrain induced by $\mathrm{A} B$.

Overall, the present study demonstrated that fluvastatin significantly prevented memory impairment induced by $A ß$. The beneficial effects of fluvastatin might be explained by the preservation of neurons through a significant decrease in $\mathrm{A} ß$ accumulation and oxidative stress. In clinical practice, the timing of the start of fluvastatin treatment might be critical in achieving a beneficial effect on cognitive function.
\end{abstract}

Correspondence to: Professor Ryuichi Morishita, Department of Clinical Gene Therapy Graduate School of Medicine, Osaka University 2-2 Yamadaoka, Suita, Osaka 565-0871, Japan

E-mail: morishit@cgt.med.osaka-u.ac.jp

Key words: amyloid $\beta$ injection mouse model, fluvastatin, antioxidative effect

\section{Introduction}

Alzheimer's disease (AD), the most common cause of dementia in the elderly, is characterized by amyloid $B$ (AB)-containing plaques and neurofibrillary tangles, and synaptic and neuronal loss, along with progressive cognitive impairment. $A \beta$, a $38-43$ amino acid peptide, is the primary component of senile plaques (1). A 3 deposited in senile plaques is considered to be primarily involved in the pathogenesis of $\mathrm{AD}$, because i) familial $\mathrm{AD}$ (FAD) has been linked to mutations in the amyloid precursor protein (APP) (2-4), and ii) FAD-linked mutations in the amyloid precursor protein (APP) and presenilin genes (5-7) result in the increased production of $\mathrm{A} \beta 42(8,9)$, which is the predominant form found in senile plaques (10). Moreover, levels of total $A B 40$ and $A ß 42$ are elevated in early dementia and levels of both peptides are strongly correlated with cognitive decline (11).

Although growing evidence suggests the beneficial effects of 3-hydroxy-3-methylglutaryl coenzyme A reductase inhibitors (statins) for $\mathrm{AD}$, this notion is still controversial. It was firstly reported that there is a lower prevalence of diagnosed $\mathrm{AD}$ in patients taking the statins, lovastatin and pravastatin, in the US (12). Another group reported that patients in the UK, receiving statins, had a lowered risk of developing dementia (13). Furthermore, it was recently reported that atorvastatin produced significant positive effects on cognitive function $(14,15)$. Consistent with clinical reports, the effect of statins on $A \beta$ metabolism has been reported in vitro and in vivo (16-18). Simvastatin reduces $A B$ levels in cell cultures and in guinea pig brain homogenate (16). Atorvastatin has been reported to activate $\alpha$-secretase, and subsequently reduce the production of $A B$ (17). However, other cohort studies indicated that lipid levels and the use of lipid-lowering agents do not seem to be associated with the risk of $\mathrm{AD}$ (19). Thus, there is an apparent discrepancy among studies regarding the effectiveness of statins for $\mathrm{AD}$. In this study, we hypothesized that the timing of the start of treatment with a statin, or the kind of statin, might be critical in achieving beneficial efficacy. Thus, we employed an Aß1-40 injection model to evaluate the effects of statins 
on memory impairment at different timings. The present study demonstrated that fluvastatin, but not simvastatin, significantly prevented memory impairment induced by $A ß$ through a significant decrease in $A B$ accumulation and oxidative stress, and the prevention of neuronal loss.

\section{Materials and methods}

Animals. Male ddY mice (6-8 weeks old) were obtained from CLEA Japan, and housed in specific pathogen-free facilities under a standard 12/12-h light/dark cycle. All experiments were carried out in accordance with the Guidelines for the Care and Use of Laboratory Animals of Osaka University School of Medicine.

Peptide and chemicals. Aß1-40 was purchased from Peptide Institute. Aß1-40 solution was prepared for each experiment as described previously (20). Briefly, $0.55 \mathrm{mg}$ A $31-40$ peptide was dissolved in $3250 \mu \mathrm{l}$ PBS with $35 \%$ acetonitrile and $0.1 \%$ trifluoroacetic acid. To remove the remaining undissolved Aß1-40, centrifugation was performed at $15,000 \times \mathrm{g}$ for $3 \mathrm{~min}$ before Aß1-40 solution was aliquoted. The control peptide Aß40-1 was also prepared in the same way as Aß1-40. Fluvastatin was provided by Novartis Pharma AG, and simvastatin was purchased from Sigma-Aldrich.

Aß1-40 injection model. To evaluate the effects of the statins on $A \beta$-induced cognitive impairment, we employed a mouse model produced by previously reported methods with modification $(21,22)$. We injected $A ß 1-40$ into the cerebral ventricle by single injection. It has been reported that the levels of total $A ß 40$ and $A ß 42$ are elevated early in dementia, and the levels of both peptides are strongly correlated with cognitive decline (11), and that the level of $A ß$ was increased 80 -fold compared with control (11). Thus, we calculated the quantity of $A \beta$ to be injected. As the basal level of $A B$ in the mouse brain is normally in the low nanomolar range, and in transgenic mouse models of brain amyloidosis it varies from 40 to $250 \mathrm{nM} / \mathrm{kg}$ body weight from 3 to 12 months of age (23), we determined the dose of Aß1-40 to be injected as $200 \mathrm{pmol} / 5 \mu \mathrm{l}$. Although the quantity of $\mathrm{A} B$ injected was relatively low as compared to that in a previous report $(21,22)$, our preliminary study revealed memory impairment induced by $A \beta$, as assessed by a water-finding task to evaluate spacial reference memory (data not shown).

Intracerebroventricular (i.c.v.) administration was carried out in accordance with a procedure described previously (22). Briefly, the mice were anesthetized with isoflulane gas and intraperitoneal xylazine and ketamine, Aß1-40 (200 pmol/5 $\mu \mathrm{l})$ was injected i.c.v. into the mice, aimed at 1 to $1.5 \mathrm{~mm}$ lateral to the midline, $0.5 \mathrm{~mm}$ posterior to the bregma, and $3 \mathrm{~mm}$ deep, using a $100 \mu 1$ Hamilton syringe with a 27 gauge needle.

Immunohistochemical detection of $A \beta$. Two days after $\mathrm{A} \beta$ injection, the mice were sacrificed by transaortic perfusionfixation with cold saline followed by $4 \%$ paraformaldehyde in $0.1 \mathrm{M}$ sodium phosphate buffer ( $\mathrm{pH}$ 7.4). The brains were removed, and postfixed for $12 \mathrm{~h}$ in the same fixative. The brains were left in $15 \%$ sucrose in sodium phosphate buffer for $24 \mathrm{~h}$, and $30 \%$ sucrose for $48 \mathrm{~h}$ at $4^{\circ} \mathrm{C}$. The frozen brains were cut at $10-\mu \mathrm{m}$ thickness with a cryostat (Leica CM3050 S, Leica Microsystems). A mouse anti-human Aß protein monoclonal antibody (6E10; Sigma) was used at a 1:200 dilution. The tissue sections were incubated overnight at $4^{\circ} \mathrm{C}$ with the primary antibody. After washing in PBS three times, the tissues were incubated for $2 \mathrm{~h}$ at room temperature with the second antibody (goat anti-mouse antibody, Alexa488 conjugate). Images were obtained by a using fluorescence microscope (Nikon Eclipse TE300, Nikon).

Water-finding task. Three weeks after $A B$ injection, the water-finding task was performed (24). Briefly, the apparatus consisted of an open field (50x30 cm with walls $15 \mathrm{~cm}$ high) with an alcove $(10 \times 10 \times 10 \mathrm{~cm}$ with ceiling) in the middle of one of the longer sides of the wall. A water bottle with a tube tip was inserted into the ceiling of the alcove. In the training trial, the mice were placed individually into one corner of the opposite side of the alcove and allowed to explore freely for $3 \mathrm{~min}$. The frequency of touching, sniffing, or licking the water tube in the alcove (number of approaches) was counted. Mice that could not find the water tube within $3 \mathrm{~min}$ were excluded from the test. The mice were immediately returned to their home cages after the training trial, and were then deprived of water for $48 \mathrm{~h}$ to be motivated to look for water. In the retention trial, the mice were placed individually in the same corner of the apparatus. To evaluate memory acquisition, drinking latency (DL) was measured as the time from placement in the corner to first touching the water tube.

Measurement of $A \beta$. The brain homogenates were analyzed by Aß40 ELISA kit (Wako Pure Chemical Industries). To extract soluble cerebral $\mathrm{A} \beta, 150 \mathrm{mg}$ of fresh frozen tissue was homogenized with a Teflon-glass homogenizer (6 strokes) in $1 \mathrm{ml}$ of $70 \%$ formic acid. Homogenates were centrifuged at $100,000 \times \mathrm{g}$ for $1 \mathrm{~h}$ to remove particular material. The supernatant was neutralized with a 20 -fold dilution in $1 \mathrm{M}$ Tris base. After neutralization, the sample was diluted with the standard diluent in the Aß40 ELISA kit and measured as directed in the package insert.

Detection of superoxide anion in brain sections. Superoxide anion was detected as described previously (25). In brief, frozen, enzymatically intact, $10-\mu \mathrm{m}$ sections were prepared from mouse brain two days after $A ß$ injection and immediately incubated with dihydroethidium (DHE) $(10 \mathrm{~mol} / \mathrm{L}$; Molecular Probes Inc.) in PBS for $30 \mathrm{~min}$ at $37^{\circ} \mathrm{C}$ in a light-protected humidified chamber. DHE is oxidized on reaction with superoxide to ethidium, which binds to DNA in the nucleus and fluoresces red. Images were obtained using a Bio-Rad Radiance 2100 laser scanning confocal microscope (Bio-Rad Laboratories, Inc.). The intensity of the fluorescence was analyzed and quantified using ImageJ.

$A \beta$ degradation assay and neprilysin assay. The mouse brain samples were homogenized on ice in $3 \mathrm{ml}$ of $0.25 \mathrm{M}$ sucrose in $50 \mathrm{mM}$ Tris- $\mathrm{HCl}$ ( $\mathrm{pH} 7.4$ ) without protease inhibitors by a Teflon-glass homogenizer for 8 strokes. The samples were centrifuged at $1300 \mathrm{x} \mathrm{g}$ for $5 \mathrm{~min}$ at $4^{\circ} \mathrm{C}$, and then the supernatant fractions were centrifuged at $100,000 \times \mathrm{g}$ for $1 \mathrm{~h}$ to 
collect membrane pellets. After washing with $100 \mathrm{mM}$ $\mathrm{Na}_{2} \mathrm{CO}_{3}(\mathrm{pH}$ 11.3), the membrane fraction was re-suspended

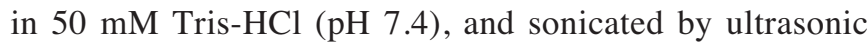
disruptor UD-201 (Tomy) at minimum power. Protein concentration was determined by a detergent compatible protein assay kit (Bio-Rad). The brain membrane fraction was used for $A ß$ degradation and neprilysin assays.

The $A ß$ degradation assay was performed as previously described (26). Briefly, 100 pM synthetic human ${ }^{125} \mathrm{I}-\mathrm{A} ß$ (2000 $\mu \mathrm{Ci} / \mathrm{mmol}$ of specific activity; GE Healthcare) was incubated with $50 \mu \mathrm{g} / \mathrm{ml}$ brain membrane fraction in $50 \mathrm{mM}$ Tris- $\mathrm{HCl}\left(\mathrm{pH} \mathrm{7.4)}\right.$ at $37^{\circ} \mathrm{C}$ for up to $4 \mathrm{~h}$. At each time point, aliquots of the reaction products were treated with $15 \%$ trichloroacetic acid (TCA) to precipitate undegraded $A B$. Following centrifugation at $16,000 \mathrm{x}$ g for $20 \mathrm{~min}$, the radioactivity of the supernatant (degradation products) and pellet (intact peptides) were measured.

Neprilysin (NEP) activity was quantified using the fluorogenic peptide substrate for NEP, N-dansyl-D-Ala-Glyp-(nitro)-Phe-Gly (DAGPNG; Sigma) (7). Briefly, $50 \mu \mathrm{g}$ brain membrane fraction was incubated with $100 \mu \mathrm{M}$ DAGPNG and $200 \mu \mathrm{M}$ enalapril (Sigma) in $0.5 \mathrm{ml}$ of $50 \mathrm{mM}$ Tris- $\mathrm{HCl}\left(\mathrm{pH} \mathrm{7.4)}\right.$ at $37^{\circ} \mathrm{C}$ for up to $2 \mathrm{~h}$. At each time point, $100 \mu 1$ aliquots were collected, and immediately biled to terminate proteolytic activity. Following centrifugation at $3000 \mathrm{x} \mathrm{g}$ for $5 \mathrm{~min}$, the fluorescence activity of the supernatant was read on a Mithras LB 940 (Berthold Technologies). The assay specificity was confirmed by the NEP inhibitor, thiorphan (data not shown).

Gel electrophoresis and Western blotting of IDE and NEP. SDS-PAGE was carried out on 4-20\% Tris/glycine gradient gel (Invitrogen). The mouse brain membrane fraction was mixed with SDS sample buffer and boiled for $5 \mathrm{~min}$ immediately prior to electrophoresis. The samples were transferred onto a polyvinylidene difluoride (PVDF) membrane (Millipore). For immunoblotting, the membranes were probed with antibodies raised to insulin-degrading enzyme (IDE) (Calbiochem) or NEP (56C6; Novocastra).

Histological analysis of choline acetyltransferase-positive cells. Two days after $A B$ injection, sections of mouse brain were prepared according to the method of $A B$ immunohistochemical analysis described above. The brain sections were incubated with $0.4 \%$ Triton in PBS at room temperature for $30 \mathrm{~min}$. Then, immunohistochemical detection of choline acetyltransferase (ChAT) was carried out with goat antiChAT polyclonal antibody (1:100 dilution; Chemicon). The brain sections were incubated overnight at $4^{\circ} \mathrm{C}$ with the primary antibody. After washing in PBS five times, the sections were incubated for $2 \mathrm{~h}$ at $4^{\circ} \mathrm{C}$ with rabbit anti-goat IgG (1:200 dilution; Chemicon). After washing in PBS five times, the sections were incubated with goat peroxidase-antiperoxidase (PAP) (1:400 dilution; Chemicon) for $2 \mathrm{~h}$ at $4^{\circ} \mathrm{C}$. Then they were washed in PBS five times and incubated in $0.05 \%$ 3,3'-diaminobenzidine tetrahydrochloride (DAB) solution (Wako Pure Chemical Industries) for $10 \mathrm{~min}$. The tissues were reacted in $0.05 \%$ DAB and $0.01 \% \mathrm{H}_{2} \mathrm{O}_{2}$ in TBS. Images were obtained by using a Nikon Eclipse TE300 optical microscope. Average numbers of ChAT-positive cells in the basal forebrain were obtained by combining the data of three consecutive coronal sections.

Statistical analysis. All values are expressed as mean + SEM. Data were statistically analyzed by Student's t-test or ANOVA. Values of $\mathrm{p}<0.05$ were considered significant.

\section{Results}

Behavioral analysis of $A \beta$-injected mice treated with fluvastatin before or after $A \beta$ injection. To test the hypothesis that the timing of the start of treatment with a statin is critical to improve the memory impairment induced by $A ß$ injection, we initially investigated the prevention of memory impairment by statin pretreatment, in which a statin was administered from 2 weeks before $A \beta$ injection, or post-treatment, in which a statin was administered from just after $A B$ injection (Fig. 1A). In the previous report on the Aß1-40 infusion model, $A ß$ accumulation was observed in the brain (21). In the present study, we observed $A ß$ accumulation in the cortex and hippocampus (Fig. 1B). Consistent with the previous reports, as assessed by the water-finding task, memory was significantly impaired in $A ß$ injection model mice. Unexpectedly, pretreatment with fluvastatin prevented the memory deficit induced by $\mathrm{A} \beta$, although post-treatment with fluvastatin did not improve memory deficit (Fig. 1C). In the training trial, the number of approaches did not vary among groups, suggesting that the opportunity for the mice to learn about the apparatus was not different among the groups (data not shown). To rule out the possibility that this difference was due to the duration of fluvastatin treatment, we also treated mice with fluvastatin for 5 weeks, from just after $A ß$ injection. However, fluvastatin treatment for 5 weeks from just after $A ß$ injection did not improve $A ß$-induced memory impairment (data not shown). Thus, the present study suggests that the beneficial effects of fluvastatin might be dependent on the time of starting the drug. To elucidate whether this beneficial effect of fluvastatin is due to the specific structure of fluvastatin or not, we tested another statin, simvastatin, in the model. Unexpectedly, mice treated with simvastatin did not perform the water-finding task better than control (Fig. 1D).

Molecular mechanisms of the improvement of memory impairment by fluvastatin. In light of the above, we examined why pretreatment with fluvastatin significantly improved memory impairment. Initially, we focused on the effects of fluvastatin on $A B$ accumulation. When $A B$ is administered into the caudate nucleus, $A B$ is metabolized and eliminated from the brain relatively rapidly (23). Thus, we measured $A B$ levels in brain homogenates at several time points after $A B$ injection by $A B$ sandwich ELISA. Interestingly, we found that pretreatment with fluvastatin significantly decreased $A B$ accumulation after $A B$ injection (Fig. 2A). Fluvastatin also significantly reduced $A B$ levels in the brain as compared with no treatment at 3 weeks after injection (Fig. 2B).

To further qualify the favorable effects of fluvastatin on $A B$ accumulation, we examined whether the decrease in $A B$ accumulation by fluvastatin might be due to an increase in $A B$ degradation activity, since $A \beta$ is mainly degraded by 
A

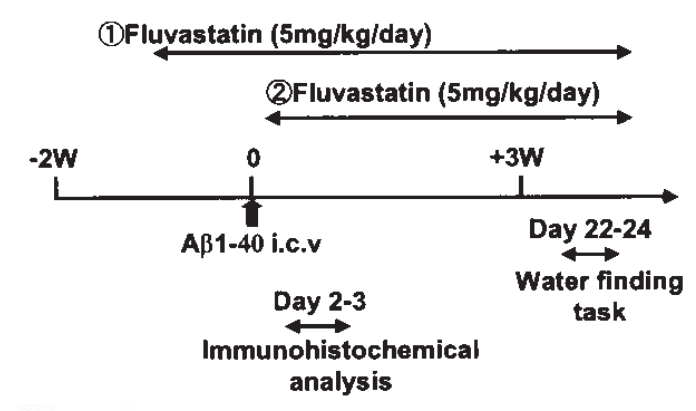

B

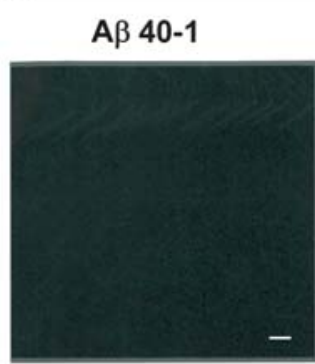

A $\beta$ 1-40 + Vehicle

C
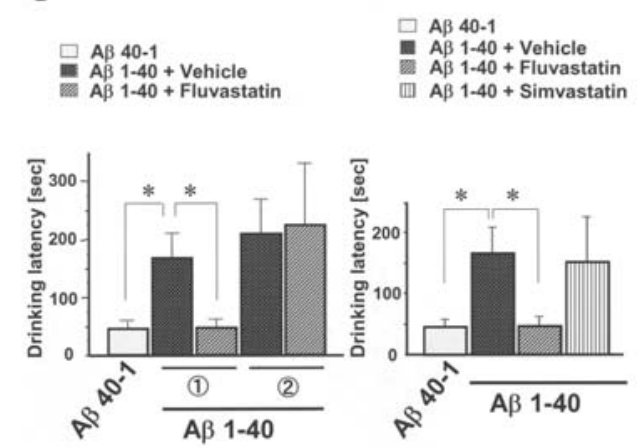

Figure 1. Behavioral analysis of $A \beta$-injected mice treated with or without fluvastatin before or after $A B$ injection. (A) Time course of fluvastatin treatment. Fluvastatin $(5 \mathrm{mg} / \mathrm{kg}$ /day) was administered for 2 weeks before (1) or just after (2) $\mathrm{A} \beta$ injection. After $\mathrm{A} \beta 1-40$ or $\mathrm{A} ß 40-1$ was injected i.c.v., mice were treated for a further 4 weeks with fluvastatin. A waterfinding task were performed 3 weeks after $A B$ injection. (B) Detection of $A B$ in the coronal section of mouse brain by immunohistochemical staining with monoclonal anti-A 3 antibody (6E10). A $340-1$, coronal section of mouse brain injected with $A ß 40-1$; Aß1-40, coronal section of mouse brain injected with Aß1-40. Scale bar, $200 \mu \mathrm{m}$. (C) Water-finding task. Drinking latency, i.e. the time $(\mathrm{sec})$ from the start to the first touch of the water bottle tube, was used for evaluation of learning. Aß40-1, mice injected with Aß40-1 $(n=10) ; A B 1-40$, mice injected with $A B 1-40$. Mice were treated with fluvastatin starting 2 weeks before (1) or just after (2) $A \beta$ injection ( $n=10$ per group). ${ }^{*} \mathrm{p}<0.05$. (D) Comparison of effects of fluvastatin and simvastatin on $\mathrm{A} \beta$-induced memory impairment in the water-finding task. Mice were treated with fluvastatin, simvastatin, or vehicle starting 2 weeks before $A B$ injection. $A B 40-1$, mice injected with $A ß 40-1 \quad(n=10) ; A ß 1-40$, mice injected with $\mathrm{A} \beta 1-40$ ( $\mathrm{n}=10$ per group). ${ }^{\mathrm{p}}<0.05$.

neprilysin (28) and insulin degrading enzyme (IDE) (29). An $\mathrm{A} \beta$ degradation assay was mainly employed to assess IDE activity $(30,31)$ while a neprilysin assay was employed to evaluate neprilysin $(27,29)$. Importantly, pretreatment with fluvastatin affected neither IDE activity nor neprilysin activity (Fig. 3A and B). Moreover, pretreatment with fluvastatin did not change the expression of NEP and IDE (Fig. 3C). These results indicate that the decrease in $A ß$
$\mathbf{A}$

B

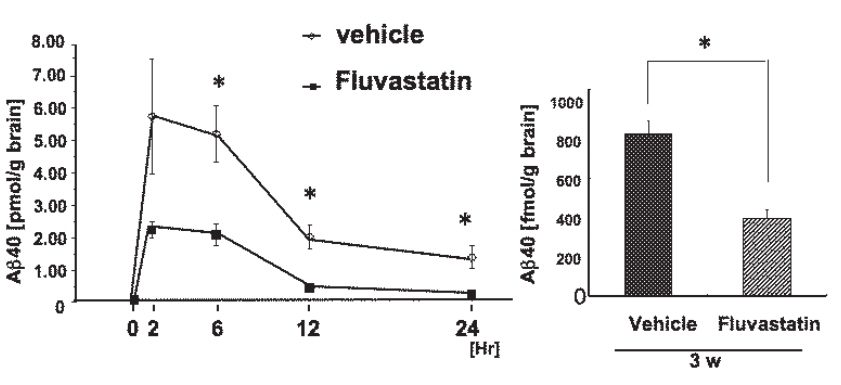

Figure 2. Effect of fluvastatin on $A B$ accumulation. (A) Quantitative analysis of $A B$ by $A B$ sandwich ELISA. $A B$ level in the mouse brain was measured just before, and 2, 6, 12, and $24 \mathrm{~h}$ after $\mathrm{A} B$ injection in mice with or without fluvastatin treatment ( $\mathrm{n}=4$ per group at each time point). ${ }^{*} \mathrm{p}<0.05$. (B) $A B$ level in the mouse brain at 3 weeks after $A B$ injection in mice with or without fluvastatin treatment ( $\mathrm{n}=3$ per group). ${ }^{*} \mathrm{p}<0.05$ vs. vehicle.

A

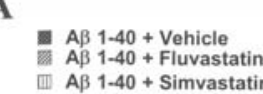

B
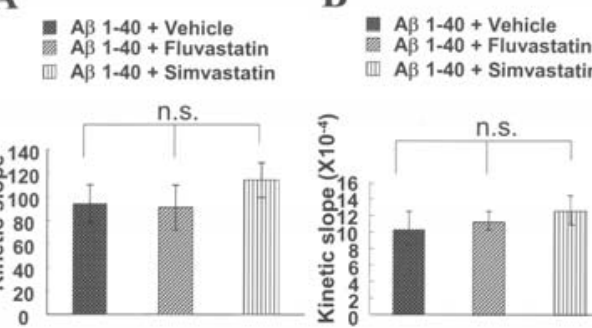

III. AB 1-40+ Simvastatin
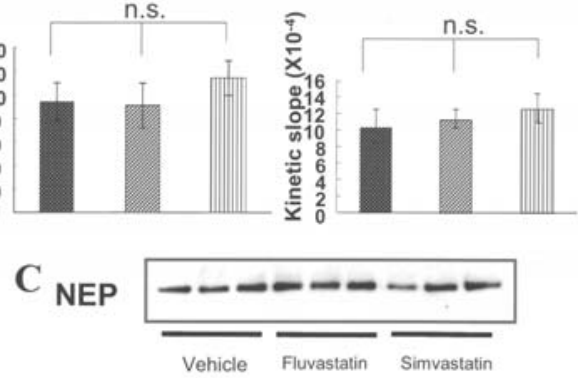

IDE

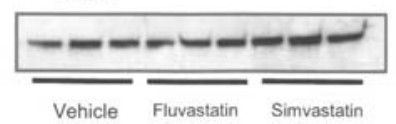

Figure 3. Effects of pretreatment with fluvastatin/simvastatin on $A B$ degradation. (A) NEP activity in mice treated with fluvastatin or simvastatin as determined by DAGPNG degradation. Vertical axis shows the kinetic slope, i.e., DAGPNG degradation per min. (B) IDE activity in mice treated with fluvastatin or simvastatin as determined by ${ }^{125} \mathrm{I}-\mathrm{A} \beta$ degradation. Vertical axis shows the kinetic slope, i.e., ${ }^{125} \mathrm{I}-\mathrm{A} \beta$ degradation per min. (C) Western blots of NEP (top) and IDE (bottom) from the brains of mice. Each group of three lanes corresponds to a set of three mice per mouse group. Mice were treated with either vehicle, fluvastatin, or simvastatin.

accumulation by fluvastatin was not through an increase in $\mathrm{A} \beta$ degradation.

We then focused on oxidative stress, since $A B$ is well known to induce oxidative stress in vivo, both in the $A \beta$ injection model $(32,33)$ and in APP transgenic mice (34). Moreover, it has been reported that fluvastatin has potent anti-oxidative effects in various models, unlike other statins (35-38). Using DHE, an oxidative fluorescent dye, to detect superoxide in brain sections (25), the present study revealed that $A B$ injection significantly induced oxidative stress in the hippocampus (Fig. 4A and B). Importantly, fluvastatin significantly reduced the oxidative stress induced by $A B$ (Fig. 4A and B). These results suggest that the anti-oxidative effects of fluvastatin may have contributed to its beneficial 
A
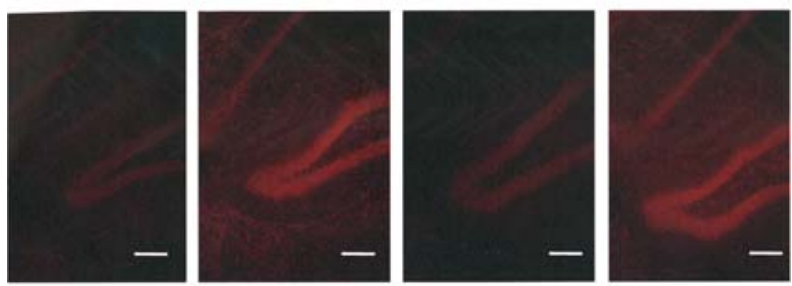

A $\beta$ 40-1

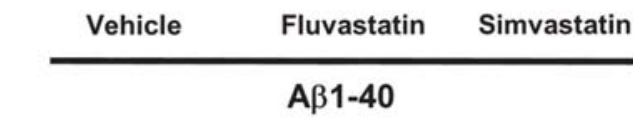

B

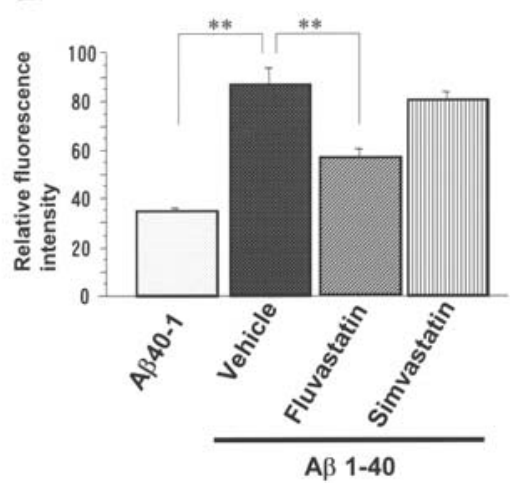

Figure 4. Effects of pretreatment with fluvastatin or simvastatin on oxidative stress induced by $A B$. (A) DHE staining of hippocampus and dentate gyrus of $A B /$ vehicle-, $A ß /$ fluvastatin-, or $A ß /$ simvastatin-pretreated mouse brains. Aß40-1, mice injected with Aß40-1; Aß1-40/vehicle, mice treated with vehicle and injected with AB1-40; AB1-40/fluvastatin, mice treated with fluvastatin and injected with $A B 1-40 ; A \beta 1-40 /$ simvastatin, mice treated with simvastatin and injected with Aß1-40. Scale bar, $200 \mu \mathrm{m}$. (B) Quantitative analysis of DHE staining in dentate gyrus. Y axis shows the ratio of fluorescence intensity in brain sections to the mean of that in brain sections of Aß40-1-injected mice. $\mathrm{n}=5$ per group. ${ }^{*} \mathrm{p}<0.001$.

effects on cognitive function. Importantly, simvastatin did not reduce oxidative stress induced by $\mathrm{A} \beta$, unlike fluvastatin (Fig. 4A and B).

Basal forebrain cholinergic neuronal loss is a common feature of $\mathrm{AD}$ (39). Moreover, this phenomenon is recapitulated in APP transgenic mice (40) and the AB injection model (22). Different effects of fluvastatin and simvastatin were also confirmed by measurement of cholinergic neurons. Fluvastatin, but not simvastatin, significantly prevented basal forebrain cholinergic neuronal loss induced by $A \beta$, whereas $A ß$ injection induced cholinergic neuronal loss in the basal forebrain (Fig. 5A and B).

\section{Discussion}

Treatment of dementia is now becoming a social problem. Among numerous possible treatments, statins might be an attractive candidate. In a French cohort study, the Three-City Study, statins were associated with decreased risk of dementia (41). However, in the Cardiovascular Health Study, a cohort study in the US, statin therapy was not associated with a decreased risk of dementia (42). The results varied in these studies, due to the limited number of subjects. On the other hand, an early report indicated that atorvastatin
$\mathbf{A}$
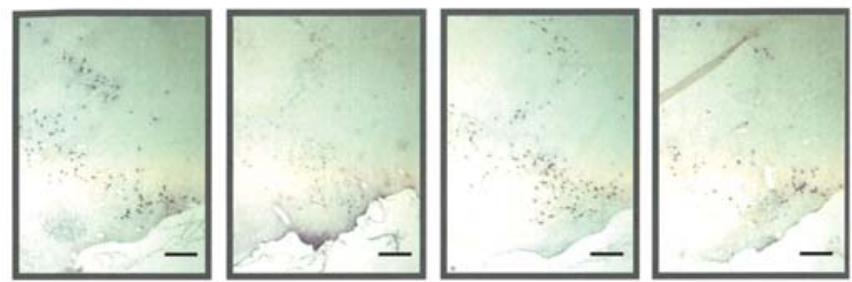

Vehicle Fluvastatin Simvastatin

A $340-1$

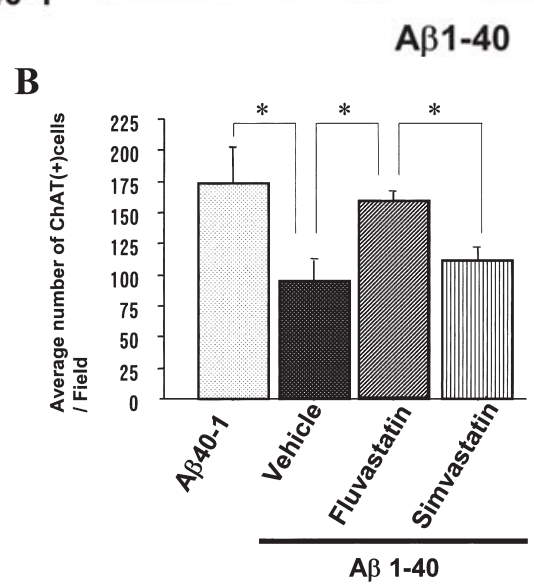

Figure 5. Effects of pretreatment with fluvastatin/simvastatin on cholinergic neuronal loss in basal forebrain induced by $\mathrm{A}$. . (A) Immunohistochemical analysis of the basal forebrain region of $A B /$ statin-pretreated mice with anti-ChAT antibody. Aß40-1, mice injected with Aß40-1; Aß1-40/vehicle, mice treated with vehicle and injected with AB1-40; Aß1-40/fluvastatin, mice treated with fluvastatin and injected with $A B 1-40 ; A \beta 1-40 /$ simvastatin, mice treated with simvastatin and injected with Aß1-40. Scale bar, $200 \mu \mathrm{m}$. (B) Average number of ChAT-positive cells in medial septal region of $\mathrm{A} \beta /$ vehicle-, $\mathrm{A} \beta /$ fluvastatin-, or $\mathrm{A} \beta /$ simvastatin-pretreated mouse brains. $\mathrm{Y}$ axis shows the average number of ChAT-positive cells obtained by combining the data in three consecutive coronal sections. $\mathrm{n}=5$ per group. ${ }^{*} \mathrm{p}<0.05$.

produced a change in the slope of deterioration of MMSE in the treatment of mild-to-moderate AD (14). These discrepancies among clinical trials indicate the need for further studies to elucidate the role of statins in the treatment of dementia. Our present study revealed two important aspects: the timing of treatment with statins, and the selection of statin. First, we clearly demonstrated that treatment with fluvastatin before the injection of $A B$ significantly prevented memory impairment induced by $A B$. Thus, the timing of administration of statins might need to be more carefully considered in clinical situations. The second question appears to be more sensitive and crucial. Our present study indicated that fluvastatin significantly improved memory impairment through a significant decrease in $A B$ accumulation and oxidative stress and a significant increase in cholinergic neurons, while simvastatin did not affect memory impairment. It has been reported that oxidative mechanisms are involved in the cell loss and other neuropathology associated with $\mathrm{AD}(43,44)$. As anti-oxidant effects of fluvastatin have been reported in patients with type 2 diabetes and hyperlipidemia as compared to simvastatin (45), the clinical comparison of anti-oxidant effects between fluvastatin and 
simvastatin might be important to elucidate the pathological significance of oxidative stress in AD. It has been suggested that the beneficial effects of statins on AD might not be only through lipid-lowering effects, but also through pleiotropic effects. One of the important mechanisms to improve memory impairment is considered to be through antioxidative effects, although further studies are necessary.

We observed that fluvastatin significantly decreased $A B$ accumulation after $A B$ injection in the model. It has been reported that cholesterol-lowering drugs and cholesterolextracting resins strongly reduce intracellular and secretory neuronal $\mathrm{A} \beta 42$ and $\mathrm{A} \beta 40$ levels in vitro, and that administration of simvastatin to guinea pigs strongly reduced cerebral $A B$ levels, including that of the $A \beta 42$ isoform (16). Another group also reported that statins inhibited the dimerization of $\beta$-secretase via both isoprenoid- and cholesterol-mediated mechanisms, and then reduced $A B$ production (46). Thus, previous studies suggested that the effects of statins were through the down-regulation of $A B$ production and/or secretion. In the present study, AB was exogenously injected and therefore, the decrease in $A ß$ accumulation by fluvastatin was not through the direct inhibition of $A \beta$ production and/or secretion, but maybe through a novel action of statins on $A B$ metabolism. The possibility that statins might affect $A ß$ degradation is not evident from the data in this study (Fig. 3). One possible explanation is related to the transport of $A B$ across the microvascular endothelium (i.e. the blood-brain barrier), since the transport of $A B$ is essential to control $A B$ levels in the brain (47). Indeed, statins have pleiotropic action on endothelial cells through the up-regulation of eNOS transcription (48), an increase in cerebral blood flow and improvement of neurological function in mice (49). Thus, these favorable actions of statins on the endothelium might up-regulate $A ß$ metabolism, including the clearance of $A ß$.

We also demonstrated that fluvastatin, but not simvastatin, rescued basal forebrain cholinergic neuronal loss induced by $A \beta$, visualized as ChAT immunoreactivity. Several studies in humans indicate that basal forebrain cholinergic pathways, especially those projecting from Meynert's nucleus to the cortex, play a crucial role in conscious awareness and mnemonic processes (50). In AD patients, a loss of brain cholinergic functions significantly contributes to the cognitive decline (51). In APP transgenic mice, neuronal damage and cholinergic dysfunction in vivo underlie the impairment of learning and memory function (52). In this study, the prevention of cholinergic neuronal loss by fluvastatin might underlie the protection against $A ß-$ induced memory impairment. The prevention of basal forebrain cholinergic neuronal loss by fluvastatin might be due to a decrease in $A \beta$ accumulation and/or inhibition of oxidative stress.

Overall, the present study demonstrated that fluvastatin, but not simvastatin, significantly prevented memory impairment induced by amyloid $B$. The beneficial effects of fluvastatin might be explained by the prevention of cholinergic neuronal loss through a significant decrease in $A ß$ accumulation and oxidative stress. In clinical settings, the timing of the start of treatment and the selection of statin might be critical in achieving a beneficial effect on cognitive function.

\section{Acknowledgements}

This work was supported in part by a Grant-in-Aid for scientific research from the Organization for Pharmaceutical Safety and Research (Japan), a Grant-in-Aid from the Japanese Ministry of Public Health and Welfare (R.M.), and Grants-in-Aid from Japan Promotion of Science, the Japanese Ministry of Education, Culture, Sports, Science and Technology (R.M., N.S.), the Takeda Science Foundation (R.M), Novartis Pharma AG, Chiyoda, and the Kanae Foundation (N.S.). We wish to thank Dr Yoshiaki Taniyama, Dr Hironori Nakagami, and Dr Takashi Miyake for helpful discussion, and Ms. Hizuki Hamada for technical assistance.

\section{References}

1. Glenner GG and Wong CW: Alzheimer's disease: initial report of the purification and characterization of a novel cerebrovascular amyloid protein. Biochem Biophys Res Commun 120: 885-890, 1984.

2. Goate A, Chartier-Harlin MC, Mullan M, et al: Segregation of a missense mutation in the amyloid precursor protein gene with familial Alzheimer's disease. Nature 349: 704-706, 1991.

3. Yoshioka K, Miki T, Katsuya T, Ogihara T and Sakaki Y: The $717 \mathrm{Val}---$ Ile substitution in amyloid precursor protein is associated with familial Alzheimer's disease regardless of ethnic groups. Biochem Biophys Res Commun 178: 1141-1146, 1991.

4. Mullan M, Crawford F, Axelman K, Houlden H, Lilius L, Winblad B and Lannfelt L: A pathogenic mutation for probable Alzheimer's disease in the APP gene at the N-terminus of betaamyloid. Nat Genet 1: 345-347, 1992.

5. Sherrington R, Rogaev EI, Liang Y, et al: Cloning of a gene bearing missense mutations in early-onset familial Alzheimer's disease. Nature 375: 754-760, 1995.

6. Rogaev EI, Sherrington R, Rogaeva EA, et al: Familial Alzheimer's disease in kindreds with missense mutations in a gene on chromosome 1 related to the Alzheimer's disease type 3 gene. Nature 376: 775-778, 1995.

7. Levy-Lahad E, Wasco W, Poorkaj P, et al: Candidate gene for the chromosome 1 familial Alzheimer's disease locus. Science 269: 973-977, 1995

8. Tamaoka A, Odaka A, Ishibashi Y, et al: APP717 missense mutation affects the ratio of amyloid beta protein species (A beta 1-42/43 and A beta 1-40) in familial Alzheimer's disease brain. J Biol Chem 269: 32721-32724, 1994.

9. Citron M, Westaway D, Xia W, et al: Mutant presenilins of Alzheimer's disease increase production of 42-residue amyloid beta-protein in both transfected cells and transgenic mice. Nat Med 3: 67-72, 1997

10. Iwatsubo T, Odaka A, Suzuk Ni, Mizusawa H, Nukina N and Ihara Y: Visualization of A beta 42(43) and A beta 40 in senile plaques with end-specific A beta monoclonals: evidence that an initially deposited species is A beta 42(43). Neuron 13: 45-53, 1994.

11. Naslund J, Haroutunian V, Mohs R, Davis KL, Davies P, Greengard P and Buxbaum JD: Correlation between elevated levels of amyloid beta-peptide in the brain and cognitive decline. JAMA 283: 1571-1577, 2000.

12. Wolozin B, Kellman W, Ruosseau P, Celesia GG and Siegel G: Decreased prevalence of Alzheimer disease associated with 3-hydroxy-3-methyglutaryl coenzyme A reductase inhibitors. Arch Neurol 57: 1439-1443, 2000.

13. Jick H, Zornberg GL, Jick SS, Seshadri S and Drachman DA: Statins and the risk of dementia. Lancet 356: 1627-1631, 2000.

14. Sparks DL, Sabbagh MN, Connor DJ, et al: Atorvastatin therapy lowers circulating cholesterol but not free radical activity in advance of identifiable clinical benefit in the treatment of mild-to-moderate AD. Curr Alzheimer Res 2: 343-353, 2005.

15. Sparks DL, Connor DJ, Sabbagh MN, Petersen RB, Lopez J and Browne P: Circulating cholesterol levels, apolipoprotein E genotype and dementia severity influence the benefit of atorvastatin treatment in Alzheimer's disease: results of the Alzheimer's Disease Cholesterol-Lowering Treatment (ADCLT) trial. Acta Neurol Scand Suppl 185: 3-7, 2006. 
16. Fassbender K, Simons M, Bergmann C, et al: Simvastatin strongly reduces levels of Alzheimer's disease $B$-amyloid peptides Abeta 42 and Abeta 40 in vitro and in vivo. Proc Natl Acad Sci USA 98: 5856-5861, 2001.

17. Parvathy S, Ehrlich M, Pedrini S, et al: Atorvastatin-induced activation of Alzheimer's alpha secretase is resistant to standard inhibitors of protein phosphorylation-regulated ectodomain shedding. J Neurochem 90: 1005-1010, 2004.

18. Thelen KM, Laaksonen R, Paiva H, Lehtimaki T and Lutjohann D: High-dose statin treatment does not alter plasma marker for brain cholesterol metabolism in patients with moderately elevated plasma cholesterol levels. J Clin Pharmacol 46: 812-816, 2006.

19. Reitz C, Tang MX, Luchsinger J and Mayeux R: Relation of plasma lipids to Alzheimer disease and vascular dementia. Arch Neurol 61: 705-714, 2004

20. Yamada K, Tanaka T, Zou LB, et al: Long-term deprivation of oestrogens by ovariectomy potentiates beta-amyloid-induced working memory deficits in rats. Br J Pharmacol 128: 419-427, 1999.

21. Nitta A, Itoh A, Hasegawa $\mathrm{T}$ and Nabeshima T: B-amyloid protein-induced Alzheimer's disease animal model. Neurosci Lett 170: 63-66, 1994.

22. Tajima H, Kawasumi M, Chiba T, et al: A humanin derivative, S14G-HN, prevents amyloid-beta-induced memory impairment in mice. J Neurosci Res 79: 714-723, 2005.

23. Shibata M, Yamada S, Kumar SR, et al: Clearance of Alzheimer's amyloid-B(1-40) peptide from brain by LDL receptor-related protein-1 at the blood-brain barrier. J Clin Invest 106: 1489-1499, 2000.

24. Nabeshima T, Noda Y and Mamiya T: The role of nociceptin in cognition. Brain Res 848: 167-173, 1999.

25. Dayal S, Brown KL, Weydert CJ, et al: Deficiency of glutathione peroxidase-1 sensitizes hyperhomocysteinemic mice to endothelial dysfunction. Arterioscler Thromb Vasc Biol 22: 1996-2002, 2002

26. Leissring MA, Lu A, Condron MM, Teplow DB, Stein RL, Farris W and Selkoe DJ: Kinetics of amyloid beta-protein degradation determined by novel fluorescence- and fluorescence polarization-based assays. J Biol Chem 278: 37314-37320, 2003.

27. Florentin D, Sassi A and Roques BP: A highly sensitive fluorometric assay for 'enkephalinase', a neutral metalloendopeptidase that releases tyrosine-glycine-glycine from enkephalins. Anal Biochem 141: 62-69, 1984.

28. Iwata N, Tsubuki S, Takaki Y, et al: Identification of the major Abeta1-42-degrading catabolic pathway in brain parenchyma: suppression leads to biochemical and pathological deposition. Nat Med 6: 143-150, 2000.

29. Leissring MA, Farris W, Chang AY, et al: Enhanced proteolysis of beta-amyloid in APP transgenic mice prevents plaque formation, secondary pathology, and premature death. Neuron 40: 1087-1093, 2003.

30. Qiu WQ, Walsh DM, Ye Z, et al: Insulin-degrading enzyme regulates extracellular levels of amyloid beta-protein by degradation. J Biol Chem 273: 32730-32738, 1998.

31. Vekrellis K, Ye Z, Qiu WQ, et al: Neurons regulate extracellular levels of amyloid beta-protein via proteolysis by insulin-degrading enzyme. J Neurosci 20: 1657-1665, 2000.

32. Shen YX, Xu SY, Wei W, Wang, XL Wang H and Sun X: Melatonin blocks rat hippocampal neuronal apoptosis induced by amyloid beta-peptide 25-35. J Pineal Res 32: 163-167, 2002.

33. Rosales-Corral S, Tan DX, Reiter RJ, Valdivia-Velazquez M, Acosta-Martinez JP and Ortiz GG: Kinetics of the neuroinflammation-oxidative stress correlation in rat brain following the injection of fibrillar amyloid-beta onto the hippocampus in vivo. J Neuroimmunol 150: 20-28, 2004.

34. Aliev G, Seyidova D, Neal ML, et al: Atherosclerotic lesions and mitochondria DNA deletions in brain microvessels as a central target for the development of human AD and AD-like pathology in aged transgenic mice. Ann NY Acad Sci 977: 45-64, 2002.
35. Yamaguchi Y, Matsuno S, Kagota S, Haginaka J and Kunitomo M: Fluvastatin reduces modification of low-density lipoprotein in hyperlipidemic rabbit loaded with oxidative stress. Eur J Pharmacol 436: 97-105, 2002.

36. Li Z, Iwai M, Wu L, et al: Fluvastatin enhances the inhibitory effects of a selective AT1 receptor blocker, valsartan, on atherosclerosis. Hypertension 44: 758-763, 2004.

37. Matsuki A, Igawa A, Nozawa T, Nakadate T, Igarashi N, Nonomura $\mathrm{M}$ and Inoue $\mathrm{H}$ : Early administration of fluvastatin, but not at the onset of ischemia or reperfusion, attenuates myocardial ischemia-reperfusion injury through the nitric oxide pathway rather than its antioxidant property. Circ J 70: 1643-1649, 2006.

38. Pat B, Yang T, Kong C, Watters D, Johnson DW and Gobe G: Activation of ERK in renal fibrosis after unilateral ureteral obstruction: modulation by antioxidants. Kidney Int 67: 931-943, 2005.

39. Geula C: Abnormalities of neural circuitry in Alzheimer's disease: hippocampus and cortical cholinergic innervation. Neurology 51: S18-S29,1998.

40. German DC and Eisch AJ: Mouse models of Alzheimer's disease: insight into treatment. Rev Neurosci 15: 353-369, 2004

41. Dufouil C, Richard F, Fievet N, et al: APOE genotype, cholesterol level, lipid-lowering treatment, and dementia: the ThreeCity Study. Neurology 64: 1531-1538, 2005.

42. Rea TD, Breitner JC, Psaty BM, et al: Statin use and the risk of incident dementia: the Cardiovascular Health Study. Arch Neurol 62: 1047-1051, 2005.

43. Zhu X, Raina AK, Lee HG, Casadesus G, Smith MA and Perry G: Oxidative stress signalling in Alzheimer's disease. Brain Res 1000: 32-39, 2004.

44. Cutler RG, Kelly J, Storie K, Pedersen WA, Tammara A, Hatanpaa K, Troncoso JC and Mattson MP: Involvement of oxidative stress-induced abnormalities in ceramide and cholesterol metabolism in brain aging and Alzheimer's disease. Proc Natl Acad Sci USA 101: 2070-2075, 2004.

45. Miwa S, Watada H, Omura C, Takayanagi N, Nishiyama K, Tanaka Y, Onuma T and Kawamori R: Anti-oxidative effect of fluvastatin in hyperlipidemic type 2 diabetic patients. Endocr $\mathrm{J}$ 52: 259-264, 2005.

46. Parsons RB, Price GC, Farrant JK, Subramaniam D, Adeagbo-Sheikh J and Austen BM: Statins inhibit the dimerization of beta-secretase via both isoprenoid- and cholesterol-mediated mechanisms. Biochem J 399: 205-214, 2006.

47. Zlokovic BV, Deane R, Sallstrom J, Chow N and Miano JM: Neurovascular pathways and Alzheimer amyloid beta-peptide. Brain Pathol 15: 78-83, 2005.

48. Hernandez-Perera O, Perez-Sala D, Navarro-Antolin J, Sanchez-Pascuala R, Hernandez G, Diaz C and Lamas S: Effects of the 3-hydroxy-3-methylglutaryl-CoA reductase inhibitors, atorvastatin and simvastatin, on the expression of endothelin- 1 and endothelial nitric oxide synthase in vascular endothelial cells. J Clin Invest 101: 2711-2719, 1998

49. Endres M, Laufs U, Huang Z, Nakamura T, Huang P, Moskowitz MA and Liao JK: Stroke protection by 3-hydroxy-3methylglutaryl (HMG)-CoA reductase inhibitors mediated by endothelial nitric oxide synthase. Proc Natl Acad Sci USA 95: 8880-8885, 1998.

50. Perry RJ and Hodges JR: Attention and executive deficits in Alzheimer's disease. A critical review. Brain 122: 383-404, 1999.

51. Bartus RT: On neurodegenerative diseases, models, and treatment strategies: lessons learned and lessons forgotten a generation following the cholinergic hypothesis. Exp Neurol 163: 495-529, 2000

52. Bellucci A, Luccarini I, Scali C, Prosperi C, Giovannini MG, Pepeu G and Casamenti F: Cholinergic dysfunction, neuronal damage and axonal loss in TgCRND8 mice. Neurobiol Dis 23: 260-272, 2006. 